\title{
Midface - cushion for head injuries
}

\author{
Mohammad Akheel ${ }^{1, *}$, Suryapratap Singh Tomar ${ }^{2}$ \\ ${ }^{1}$ Dept. of Oral \& maxillofacial surgery, NDCH, Nellore, VGN laparaisene, Nolambur, Mogappair west, Chennai 600037, T.N., India \\ ${ }^{2}$ Senior registrar, Dept. of Neurosurgery, NMCH, Nellore, A.P., India
}

\section{Email address:}

drakheelomfs@gmail.com (M. Akheel)

\section{To cite this article:}

Mohammad Akheel, Suryapratap Singh Tomar. Midface - Cushion for Head Injuries. Science Journal of Public Health.

Special Issue: Health Behavior and Public Health. Vol. 3, No. 1-1, 2015, pp. 29-32. doi: 10.11648/j.sjph.s.2015030101.15

\begin{abstract}
Recent technological advances have led to improvements in social well being of man's life in all aspects. This improving and advanced lifestyle is the major cause for some debilitating problems like road traffic accidents. Statistical analysis in literature shows that head and maxillofacial injuries are the most common of these injuries. Recent studies show that fractures of midface are strongly associated with a high mortality rate. The exact relationship between different types of facial fractures and brain injuries is still controversial. Purpose: To evaluate the individuals with fractures of midface from different etiologies and determine if there is any relationship between various fractures of midface acting as a buffer mechanism for head injuries. Materials and Methods: Retrospective study was done to assess all the patients with midface fractures at the trauma center in a rural area in India. The etiologic and demographic data, the type of midface fracture and brain injury, and Glasgow coma scale were assessed. Results: Of 59 patients, 33 patients had head injury. The important correlations were as follows: Le Fort III with brain contusion, nasal orbital ethmoid fractures with subdural hematoma, frontal fracture with subdural hematoma, zygomatic complex fracture with brain contusion. Nasal fracture correlated with brain contusion. The zygomatic complex fracture was the most prevalent fracture. Conclusion: Different midface fracture patterns have the risk of different types of simultaneous brain injuries. So midface fractures absorb the forces of impact to a great extent and prevent the severity of head injuries and high mortality rate.
\end{abstract}

Keywords: Maxillofacial Trauma, Head Injury, Road Traffic Legislation

\section{Introduction}

Maxillofacial fractures and associated head injury has been the focus of numerous investigations over the past 2 decades. This is due to recent advancements in the life style and change in trends in society. Historically, the facial architecture especially the midface has been perceived as a cushion against impact of force protecting the neurocranium from severe injury. However, some recent literatures have suggested that the forces acting on face may actually transmit them directly to the neurocranium, resulting in more serious brain injury.

Patients with fracture of midface are always at risk for accompanying head injuries, which should be identified before the patient deteriorates[1] Midface includes developmental facial sutures and paper thin bones that make it susceptible to fracture even with minimal external forces. The proximity of the midfacial bones to the neuocranium would suggest that there are chances of cranial injuries occurring simultaneously. High mortality rate due to these fractures are related with injuries of the other parts of body such as brain that might be life threatening. Many of these mortalities are preventable by a early systematic clinical and radiological diagnosis [2]. The prevalence of neurologic injury associated with midfacial fractures has been reported to be as high as 76\% [3] But according to recent studies in literature, the exact relationships between types of midfacial fractures and head injuries have yet to be established. In this retrospective analysis, we assess whether fractures of midface act as cushion to prevent major head injuries.

\section{Materials and Method}

This is a retrospective study done on 59 patients to assess the patients with midface fractures at the trauma center of Narayana general hospital, A.P., India covering a rural population of more than 10 lacs from the district. The 
etiologic and demographic data, the type of midface fracture and brain injury, and Glasgow Coma Scale (GCS) scores were assessed. Midfacial fractures were divided into isolated nasal fixation, zygomatic fixation, nasal orbital ethmoid complex fixation, frontal fixation, Le Fort I, II, III. All the patients were assessed by oral and maxillofacial surgeons thoroughly with the help of clinical and radiological investigations. Brain injuries include epidural hematoma, intracranial hemorrhage, subdural hematoma, pneumocephalus and brain contusion. All neurologic injuries were systematically diagnosed by expert neurosurgeons The types of midfacial fractures were then correlated with the type of head injury and Glasgow Coma Scale (GCS) scores as reported by Teasdale and Jennett ${ }^{4}$. GCS is used as a method of neurologic evaluation in head injury patients, denoting the severity and prognosis of injury.

\section{Results}

Of 59 patients, which included 45 males and 14 females, 33 patients had head injury most common being minor brain contusions. Lefort I fracture was seen in $4 \%$, Lefort II \& III fracture in $21 \%$, zygomatic complex fractures in $38 \%$, Frontal bone fracture in $6 \%$, Naso-orbito-ethmoid fracture in $16 \%$ and nasal fracture in $22 \%$. (Fig 1). The prevalence of head injuries was pneumocephalus in $15 \%$, brain contusion in $19 \%$, Extradural hematoma in $9 \%$, subdural hematoma in 6\%, Intracranial hemorrhage in $7 \%$ and in $44 \%$ of patient there was no injury. The zygomatic complex fracture was the most prevalent of all the midfacial fractures. The important correlations were as follows: Le Fort III with brain contusion, nasal orbital ethmoid fractures with subdural hematoma, frontal fracture with subdural hematoma, zygomatic complex fracture with brain contusion. Nasal fracture correlated with brain contusion.

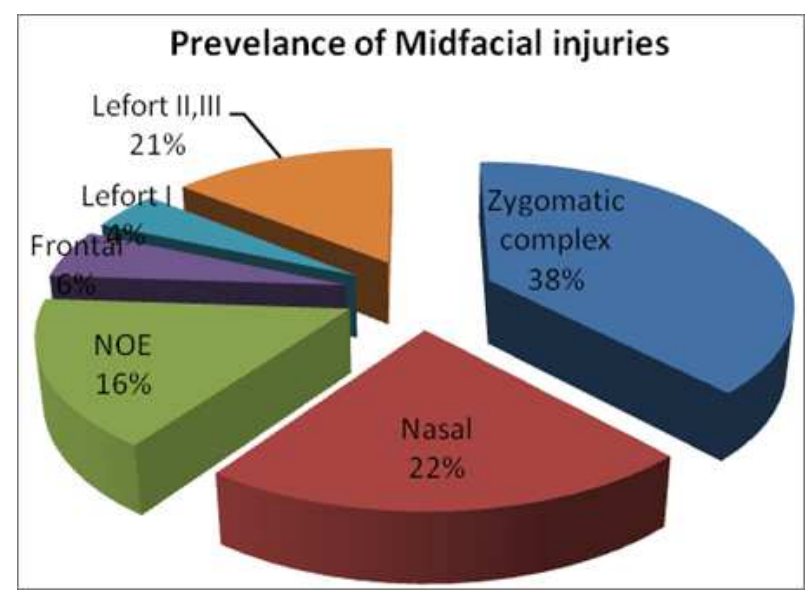

Fig 1. Prevelance of midface injuries

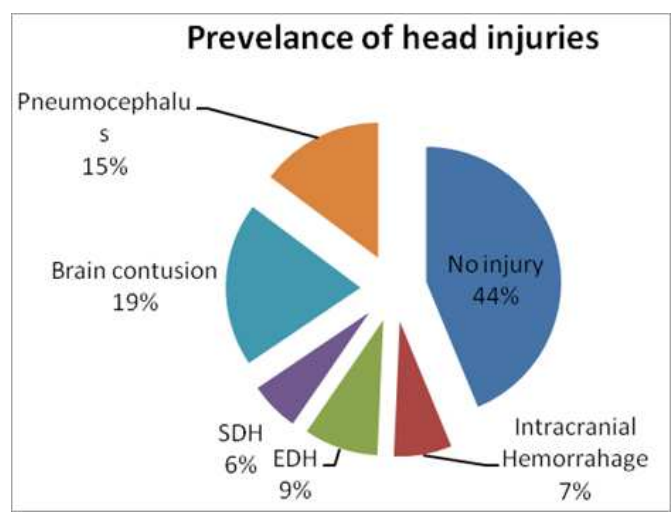

Fig 2. Prevelance of head injuires

\section{Discussion}

The zygomatico-maxillary complex, due to its prominent position in the face bears the impact of trauma in majority of the cases and has been shown to have the highest incidence of fractures in the maxillofacial region. Trauma in general terms is regarded as the disease of men and the youth. This assertion is further corroborated by the present study in which most of the patients here were men within the 20-29 year age bracket. The main reason among others is the fact that motorbikes are mostly ridden by young men for commercial purpose in our environment and motorbikerelated accidents accounted for $45.5 \%$ of all the midface injuries in this series. This pattern is in keeping with similar studies both in the developed and the developing world. The prominence of the zygomatic complex as well as its multiple articulations with other bones of the facial skeleton renders it exceptionally vulnerable to fracture when injuries affect the maxillofacial region. The statistical analysis of this study establishes that the facial structures protect the brain from injury acting as a shock absorber and transmitting very minimal forces to the cranium and the brain. It has been always a controversy whether or not head injuries can be inter-related with facial fractures and is an important dilemma with clinical implications. Head injury has become a global epidemic and its radiological evaluation has evolved from conventional radiography to modern cross-sectional imaging techniques like computed tomography (CT) scans and magnetic resonance imaging (MRI). Conventional radiographs relied mostly on skull views and special projections to demonstrate the orbits, paranasal sinuses, temporal bones, and base of the skull.

Haug et al[5] advocated from his study that one third of the patients with facial fractures had some kind of underlying neurologic injury. But still there is a general lack of literature specifically in relation to maxillofacial surgery pertaining to associated injuries in general, and head injuries in particular.The relationship between midfacial fractures and head injuries is one of the most critical subjects to be studied in the field of trauma and health care. Several authors put forward several studies describing a large series of facial fractures but none is conclusive[6,7.8 ]Although at first it was thought that this 
incidence was high, review of literature search indicated that the frequency of head injury associated with midfacial fracture was as high as $76 \%[9,10]$

The adjacent position of the face and brain would determine if the midfacial structures can act as shock absorber for brain. Midface absorbs some forces from the brain but not all. This study shows that some part of head injury occurs with midfacial fractures but the severity of the injury is always low because of major amount of forces absorbed by midfacial structures. In head injuries, various studies show brain concussion to be more commonly associated with midfacial fractures [11,12]In intracranial injury, cerebral contusion was seen more frequently. Keenan et al found that incidence of brain concussion was $9 \%$ and intracranial injury was $4 \%$ in his study [6] The proximity of the midface to the eyes and the content of the cranium could as well have accounted for this. Hogg et al. also reported head injuries to have accounted for $87 \%$ of the associated injuries in their study in Ontorio, anada, whereas Obuekwe and Etetafia reported $55.8 \%$ of head injuries in Benin City, Nigeria. This wide range is probably due to different selection criteria and methods of detecting brain injury. Recognizing concomitant injuries in patients with facial fracture is important for rapid assessment and further management of these patients [13,14].

According to our findings from the study (Fig 1and 2), Naso-Orbital-Ethmoid (NOE) complex fractures were the most related fracture with the head injuries (anterior brain injuries) we measured, and except with Pneumocephalus, they were significantly related with all head injuries. Among midfacial fractures, Le Fort II and Frontal fractures increase the risk of intracranial hemorrhage. Totally, all of the midfacial fractures in our study had a relationship with a head injury though not severe but to minimal extent. So, it can be claimed that midfacial fractures may increase the risk of brain injuries. According to the results, it seems that the lesser the trauma force is, the lesser the brain injury risk

Males are more susceptible for midface fracture than females due to their more active presence in the society in our context. Most of our patients were in the age range of 16- 45 that is similar with the results of Tanaka et al [15].The midfacial fracture pattern and etiology are quite different in different countries. Previous studies have indicated that car accidents are the first cause of midface fractures in US and Europe. However, recent studies have shown that the main cause is Assault and interpersonal conflicts. Our study shows in India, road accidents are the main cause of midfacial fracture. This difference in accident rate can be due to negligence of driving rules and regulations. Hence a strict law has to be reinforced to follow the traffic rules and regulations. Diagnosis of head injuries due to midrace fracture on the proper time can prevent irreversible effects and even death in patients. Therefore, midface fractured patients must be studied from all different aspects.

Hence from this study it can be concluded that every midfacial fracture patients must be carefully evaluated clinically and radiologically to rule out any underlying head injury and decreased the incidence of mortality rate. Most of the midfacial fractures absorbs forces and minimizes the head injuries. There must be public awareness regarding the road traffic accidents and laws by the government must be followed strictly by the public to prevent these maxillofacial injuries. The incidence of midfacial trauma secondary to RTA can be reduced by enactment of appropriate legislation directed at the widespread installation of air bags into all motor vehicles and helmet use by cyclists and enforcement of traffic rules to minimize RTAs.

\section{References}

[1] Pappachan B, Alexander M. Correlating facial fractures and cranial injuries. J Oral Maxillofac Surg 2006; 64: 1023-1029.

[2] Kraus JF, Rice TM, Peek-Asa C, McArthur DL. Facial trauma and the risk of intracranial injury in motorcycle riders. Ann Emerg Med 2003; 41: 18-26.

[3] Keenan HT, Brundage SI, Thompson DC, Maier RV, Rivara FP. Does the face protect the brain? A casecontrol study of traumatic brain injury and facial fractures. Arch Surg 1999; 134: 14-17.

[4] Teasdale G, Jennett B. Assessment of coma and impaired consciousness. A practical scale. Lancet 1974; 2(7872): 8184.

[5] Haug RH, Prather J, Indresano AT. An epidemiologic survey of facial fractures and concomitant injuries. J Oral Maxillofac Surg 1990; 48: 926-932.

[6] Ozkaya O, Turgut G, Kayali MU, Uğurlu K, Kuran I, Baş L. A retrospective study on the epidemiology and treatment of maxillofacial fractures. Ulus Travma Acil Cerrahi Derg 2009; 15: 262-266.

[7] Keenan HT, Brundage SI, Thompson DC, Maier RV, Rivara FP. Does the face protect the brain? A casecontrol study of traumatic brain injury and facial fractures. Arch Surg 1999; 134: 14-17.

[8] Rowe NL, Killey HC: Fractures of the facial skeleton. 2nd ed., Livingstone: London; 1968. p. 857.

[9] Turvey TA. Midfacial fractures: a retrospective analysis of 593 cases. J Oral Surg 1977; 35: 887-891.

[10] Adekeye EO. The pattern of fractures of the facial skeleton in Kaduna, Nigeria. A survey of 1,447 cases. Oral Surg Oral Med Oral Pathol 1980; 49: 491-495.

[11] Brandt KE, Burruss GL, Hickerson WL, White CE, DeLozier JB 3rd. The management of midface fractures with intracranial injury. J Trauma 1991; 31: 15- 19.

[12] Lee KF, Wagner LK, Lee YE, Suh JH, Lee SR. The impactabsorbing effects of facial fractures in closedhead injuries. An analysis of 210 patients. J Neurosurg 1987; 66: 542-547.

[13] Obuekwe ON, Etetafia M. Associated injuries in patients with maxillofacial trauma. Analysis of 312 consecutive cases due to road traffic accident. J Med Biomed Res. 2004;3:30-6. 
[14] Hogg NJ, Stewart TC, Armstrong JE, Girotti MJ. Epidemiology of maxillofacial injuries at trauma hospitals in Ontario, Canada, between 1992 and 1997. J Trauma. 2000;49:425-32.
[15] Plaisier BR, Punjabi AP, Super DM, Haug RH. The relationship between facial fractures and death from neurologic injury. J Oral Maxillofac Surg 2000; 58: 708-712 